\title{
SOBRE O TÓPICO SENTENCIAL, ALGUMAS CONSIDERAÇÕES
}

\section{Jair Barbosa da Silva *}

Resumo: Neste artigo, far-se-á uma breve revisão na literatura sobre o tópico sentencial, item bastante mencionado nos estudos lingüísticos de base formal e funcional, mas ainda carente de estudos mais detalhados. A discussão que faremos neste espaço, no entanto, será pautada apenas nos trabalhos de orientação funcionalista sobre o tópico. Para tal, lançaremos mão dos trabalhos de Pontes (1987), Givón (1995) e Pezatti (1992 a 1998).

Palavras-chave: Tópico. Ordem de palavra. Funcionalismo.

\section{Introdução}

Certamente o termo tópico é bastante veiculado no âmbito da literatura lingüística, seja ela de base formal ou funcional. No entanto, essa categoria lingüística não é tratada de forma comum entre as perspectivas de abordagens da língua - e nem poderia - o que pode causar algum tipo de equívoco aos mais ingênuos ou mesmo àqueles estudiosos experientes mais radicais. Isso se justifica porque cada perspectiva lingüística analisa o tópico sob um viés específico, portanto, quando um formalista fala em tópico, necessariamente não está tratando do mesmo tópico de que falam os funcionalistas. E mesmo entre estes há divergências, o que parece justificar-se por haver, como lembra Neves (1997), a existência de funcionalismos.

A título de ilustração veja-se o que alguns dicionaristas definem como sendo tópico. Para Dubois (1993, p. 590), tópico é o mesmo que tema. 
Numa frase assertiva, chama-se tema o constituinte imediato (sintagma nominal) a respeito do qual se diz alguma coisa (predicado): o tema pode ser ou não sujeito da frase. Por exemplo: o livro e Pedro são temas das frases seguintes: O livro está na mesa e Foi Pedro que eu vi ontem (DUBOIS, 1993, p. 581).

\section{Já para Crystal (2000, p. 255) o tópico é o}

Termo usado na SEMÂNTICA e na GRAMÁTICA como parte de uma caracterização binária da ESTRUTURA DA SENTENÇA, alternativa à caracterização tradicional SUJEITO-PREDICADO; o oposto de tópico é COMENTÁRIO. O tópico de uma sentença é a pessoa ou coisa sobre a qual se fala algo, enquanto que o que se falou a respeito desta pessoa ou coisa é o comentário. A utilidade da distinção é permitir afirmaçōes gerais sobre as relaçōes entre as sentenças que não ficam claras com a distinção sujeito/predicado (ou outros contrastes do mesmo tipo). O tópico freqüientemente coincide com o sujeito da sentença (ex.: Um homem/está se aproximando de casa), mas não necessariamente (Lá está o homem / que me ajudou) e, mesmo quando é um sujeito, não precisa vir em primeiro lugar na sentença (ex.: José Silva meu nome ć). Às vezes, é chamado de "sujeito psicológico".

Em Camara Jr. (1986), não há menção ao termo tópico ou tema, ao menos enquanto verbetes. Aliás, o autor faz sim menção ao termo tema, mas na acepção mórfica da coisa. Ou seja, enquuanto parte do vocábulo flexional.

Como se pode observar, a noção de tópico é bem abrangente e também distinta de autor para autor. Os dicionaristas citados apenas demonstram as várias possibilidades de se lidar com essa categoria lingüística. É bem verdade que não se pode exigir de um dicionarista uma definição de um verbete que dê conta dum item específico por 
completo. Ainda assim é notória a distinção feita pelos autores ou a insuficiência delas. Ora, dizer que o tópico de uma sentença "é a pessoa ou coisa sobre a qual se fala algo", além de ser insipiente, pode levar o leitor incipiente a crer que tópico e sujeito são a mesma coisa como, aliás, sugere Crystal (2000). Em se consultando uma gramática de língua portuguesa, o conceito mais comum que se pode encontrar de sujeito é este: ser ou coisa sobre o/a qual se diz algo. Dessa forma, parece ser insuficiente a definição de Crystal acerca do tópico, como a de Dubois também o é.

Se, num simples confronto de verbetes de dicionários, encontram-se pontos de vista tão divergentes sobre o tópico, imagine-se quando se buscam referências acerca do assunto em autores diversos, de orientação teórico-lingüística distinta. É o que será feito no decorrer deste artigo com a finalidade de se discutir a pertinência das propostas apresentadas pelos autores selecionados.

Para os fins deste trabalho, serão tomados por base três autores de orientação funcionalista, cujos trabalhos versam sobre o tópico sentencial, a saber: Pontes (1987), Givón (1995) e Pezatti (1992 a 1998). A seqüência cronológica dos trabalhos não foi feita propositadamente, porém parece sugerir que está havendo certa preocupação em se empreender pesquisas sobre o assunto. Também se faz necessário ressaltar que os três autores ora citados, apesar de tomarem o Funcionalismo como base norteadora de seus trabalhos, adotam perspectivas distintas a respeito do tópico.

É claro que essa questão não anula, em hipótese alguma, a co-relação entre os autores. Primeiro porque o tópico é uma categoria comum a todas as perspectivas de estudo funcional; segundo porque, como bem sugere Neves (1997), não há apenas um funcionalismo, mas funcionalismos, o que permite abordagens diferenciadas dos fenômenos lingüísticos e no caso em particular, do tópico.

A proposta de cada autor será exposta na seqüência seguinte: Pontes, Givón e Pezatti. Sempre que possivel, além de apresentar o que defendem os autores do ponto de vista teórico, far-se-á a 
exposição de suas análises a fim de se verificar como abordam a questão do tópico e dela dão conta. Para fins metodológicos de ilustração das teorias expostas pelos autores, serão usados os exemplos por eles propostos, bem como sentenças de conversação espontânea coletadas pelo autor deste texto.

\section{A proposta dos autores}

\subsection{Pontes}

A obra de Pontes a que se faz referência neste trabalho está subdividida em sete capítulos, os quais podem ser lidos separadamente. São artigos que fazem parte da experiência acadêmica da autora de 1980 a 1982 e que, reunidos em livro, com o título de O tópico no português do Brasil, abordam, não só a questão do tópico, mas também outros temas a ele relacionados, como a ordem dos constituintes sentenciais na oração. Para este trabalho, serão úteis, em especial, os capítulos um - Da importância do tópico em português e três - Topicalização e deslocamento para a esquerda -, em que a autora centra sua discussão no tópico.

Para Pontes (1987), com base na tipologia das línguas proposta por Li e Thompson (1976), as línguas são divididas em quatro tipos:

a) Línguas com proeminência de sujeito, em que a estrutura das sentenças é bem mais descrita como de sujeito-predicado;

b) Línguas com proeminência de tópico, em que a estrutura das Ss é bem mais descrita como de tópico-comentário;

c) Línguas com proeminência de tópico e sujeito, em que há duas construções diferentes;

d) Línguas com proeminência de sujeito ou tópico, em que o sujeito e o tópico se mesclaram e não se distinguem mais os dois tipos. 
Após apresentar a tipologia acima transcrita, a autora cita exemplos de línguas que se encaixam numa ou noutra tipologia e diz que o português, apesar de ter sido considerado por muito tempo uma língua com proeminência de sujeito, pode ser, hoje, considerado com proeminência de tópico, uma vez que a quantidade de ocorrência de construções tópicas na modalidade oral é muito abundante. A autora, referindo-se às construções tópicas, ainda diz que "a maioria delas ainda não foi objeto de nenhum estudo detalhado até o momento" (PONTES, 1987, p. 12), o que parece ser verdadeiro. Uma busca na literatura sobre o assunto é suficiente para se perceber a pouca consistência dos trabalhos publicados ou uma grande dificuldade em se estabelecer o que, de fato, é um tópico ou ainda como essa categoria é configurada na língua.

Uma questão relevante apontada pela autora diz respeito ao fato de que fazer o estabelecimento do tipo de uma língua năo é fácil, haja vista que lingüistas e gramáticos partem do "pressuposto de que sujeito-predicado é uma construção universal". A esse respeito, o trabalho de Pezatti não apresenta dificuldades, pois a autora, tomando por base a proposta de Dik (1981 a 1989), sugere que as noções de sujeito e predicado são de competência da sintaxe, ao passo que a noção de tópico é de competência da pragmática.

Em sendo assim, parece não haver necessidade de se fazer uma tipologia das línguas tomando-se como referência a proeminência de sujeito ou de tópico, uma vez que são aspectos pertencentes a níveis de análise distintos - sintaxe e pragmática, respectivamente - parecem ser categorias co-existentes, pois. Para Pontes (Op. Cit.), sobretudo no português coloquial informal, é comum encontrarmos sentenças como:

Muito embora a autora refira-se ao seu tempo - 1987 -, considerando-se o ano de publicação do livro, ainda hoje essa realidade é evidente. 


\section{(1)}

a) Essa bolsa as coisas somem, aqui dentro.

b) Essa bolsa aberta aí, eu podia te roubar a carteira.

c) As cadeiras optativas, cê precisa ter um conhecimento bom primeiro.

d) Eu agora, cabô desculpa de concurso, né? (PONTES, 1987, p. 13)

Conforme Chafe, Li e Thompson (1976 apud PONTES, 1987, p. 13) "o que caracteriza o tópico nas línguas como o chinês" é ele estabelecer um quadro de referência para o que vai ser dito a seguir". Segundo a análise de Pontes (1987), o comentário é sempre feito com uma estrutura completa, ou seja, com sujeito e predicado. Para ela a relação estabelecida entre o comentário e o tópico das Ss (sentenças) acima é apenas semântica. Na visão da autora "não se pode dizer que um elemento da sentença-comentário foi "topicalizado"'. O SN "as cadeiras optativas", aos olhos da autora, não é possível de ser considerado como um caso de deslocamento para a esquerda da "construção completa" - sujeito/predicado.

Para sustentar sua argumentação, Pontes diz que o contexto em que a sentença foi produzida não permite interpretações do tipo "As cadeiras optativas, cê precisa de um conhecimento bom antes de cursá-las". Quanto à análise de Pontes, parece razoável aceitar que o SN "as cadeiras optativas" não pode ser interpretado simplesmente como um deslocamento para a esquerda do referido SN. Pontes (Op. Cit., p. 13 )"a relação entre o tópico [referindose ao constituinte "as cadeiras optativas"] ao e o comentário é puramente semântica".

No tocante à proposta de Pontes para a questão do tópico, convém lembrar a ênfase dada ao discurso, aqui entendido como

A referência aqui ao chinês é feita por ser esta língua considerada como uma língua com proeminência de tópico. Os autores citados por Pontes, e ela mesma, vão ao extremo de dizer que o verdadeiro tópico é o do chinês. 
fala mais todo o contexto em que ela ocorre, pela autora. Na sentença "O Mardônio pifou o freio de mão do carro e ele foi levar na oficina", construção similar à ocorrência do tópico chinês, foi proferida num contexto em que se perguntou "E o Mardônio?"; daí, segundo a autora, o porquê de a sentença começar com esse SN, ou seja, há, nesse caso, uma retomada do que foi dito antes.

Pontes, a certa altura de seu trabalho, sente a necessidade de fazer esclarecimentos sobre a possível ambigüidade da palavra tópico. "Essa palavra tem sido usada na literatura sobre discurso, com um sentido mais geral, próximo de assunto", sentido previsto tanto na proposta de Pezatti como na de Givón . Contudo, Pontes (1987, p. 15) diz usar o termo tópico num sentido mais restrito, "referindo-se a construções que estão mais próximas da sintaxe, eu diria que no limiar entre a sintaxe e o discurso". A grande questão é saber qual o limiar entre sintaxe e discurso. Pontes fala de uma "quase-sintaxe"; isso existe? Não seria mais adequado pensar que determinados usos discursivos (entenda-se como fala em contextos e com finalidades específicos) configuram determinadas construções sintáticas como as construções tópicas? Uma questão a ser (re)pensada.

Ainda citando Chafe sobre o "quadro de referência" característico do tópico, Pontes diz que este pode ser espacial, temporal ou individual. Para Chafe, no inglês ocorrem construções similares ao chinês com determinados advérbios temporais como em "Tuesday I went to the dentist"; no inglês, no entanto, na maioria dos casos a preposição é obrigatória, ao contrário do chinês. Nesse sentido, as construções do português coloquial, afirma Pontes, estão mais próximas do chinês, uma vez que é bastante comum o não uso da preposição, como se pode ver nos dados a seguir. 
(2)

a) O sell apartamento entra muita poeira?

b) Agora o CESMAC tudo é pago.

c) Recife tá uma violência terrivel.

d) A UFAL, à noite, as aulas vai até dez horas e olhe lá.

e) Próximo ano ell só vô tirá dez em Matemática. ${ }^{3}$

"Numa abordagem transformacional, dir-se-ia que quando se topicaliza o adjunto adverbial temporal ou de lugar, suprimese a preposição" (PONTES Op. Cit., p. 17). Para Pontes, as ocorrências topicalizadas não são um privilégio dos locativos e dos indicadores de tempo. Em Português, qualquer SN pode ser topicalizado, portanto.

Faz-se ainda necessário ressaltar dois aspectos importantes da proposta de Pontes: o primeiro diz respeito às características do tópico nas línguas de tópico; o segundo, às características das línguas de tópico. Esses dois aspectos estão sintetizados nos quadros a seguir.

3 Dados coletados pelo autor do presente artigo de conversas informais entre universitários. O procedimento adotado para tal restringiu-se à anotação do dado na situaçăo em que ele foi produzido (corredores da Universidade Federal de Alagoas), visando exatamente a discussäo posterior na Dissertação de Mestrado da qual este texto é subparte. Saliente-se que os registros foram feitos mantendo-se a originalidade da forma como foram proferidos. Por outro lado, o uso do itálico foi uma opção do autor para colocar todos os dados mencionados no texto, como forma de destacar ou de diferenciar os dados do texto em si. 
1. CARACTERÍSTICAS DO TÓPICO NAS LÍNGUAS DE TÓPICO ${ }^{4}$

\begin{tabular}{|l|c|c|}
\hline \multicolumn{1}{|c|}{ CARACTERÍSTICA } & TÓPICO & SUJEITO \\
\hline DEFINIÇĀO & + & - \\
\hline RELAÇÕES SELECIONAIS & - & + \\
\hline DETERMINADO PELO VERBO & - & + \\
\hline PAPEL FUNCIONAL & + & - \\
\hline CONCORDANCIA VERBAL & - & + \\
\hline POSIÇÃO INICLAL NA SENTENÇA & + & - \\
\hline PROCESSOS GRMATICAIS & - & + \\
\hline
\end{tabular}

\section{CARACTERÍSTICAS DAS LÍNGUAS DE TÓPICO}

\begin{tabular}{|l|l|}
\hline \multicolumn{1}{|c|}{ CARACTERÍSTICA } & \multicolumn{1}{c|}{ OCORRÊNCIA EM PORTUGUÊS } \\
\hline PASSIVIZAÇÃO & Não há ou é muito rara. \\
\hline SUJEITOS VAZIOS & $\begin{array}{l}\text { Não há, diferentemente do inglês e do francês, } \\
\text { com o it e o il, respectivamente. }\end{array}$ \\
\hline "DUPLO SUJEITO" & Ocorre, o que é típico das línguas de tópico. \\
\hline CO-REFERÊNCIA & É estabelecida com o tópico e não com o sujeito. \\
\hline RESTRIÇÕES DO TÓPICO & Não há, qualquer SN pode ser tópico. \\
\hline SENTENÇAS BÁSICAS & $\begin{array}{l}\text { As sentenças de tópico não são derivadas; são } \\
\text { por elas mesmas básicas. }\end{array}$ \\
\hline
\end{tabular}

As características expostas nos dois quadros acima são adotadas por Pontes de Li \& Thompson (1976) e, apesar dos seus

4 É importante considerar alguns fatores, quando da leitura do quadro acima, a saber: I. a oposiçăo tópico/sujeito se deu porque se levou em conta a questão das línguas em que se tem proeminência de tópico em relaçăo às que têm proeminência de sujeito; II. todas as características referentes ao tópico são bastante rígidas, mas isso nāo implica a impossibilidade de haver uma ou outra que supere essa rigidez. A concordância, apesar de muito rara, exatamente porque o verbo seleciona o sujeito e não o tópico, pode se dar com o tópico. 
quase 30 anos, ainda são bastante atuais, no sentido de que dão conta das ocorrências de tópico no português falado. Com isso, está-se admitindo que a proposta de Pontes para análise das sentenças de tópico se faz coerente, dentro do quadro teórico adotado por ela. É claro que alguns aspectos pela autora adotados, como a noção de deslocamento à esquerda ${ }^{5}$, parecem não mais fazer sentido para os estudos da sentença, sob a ótica do funcionalismo. Convém lembrar, todavia, que isso é passível de alguma relatividade, se se considera a existência de funcionalismos diversos, como já foi mencionado anteriormente.

\subsection{Givón}

Givón (1995) concebe o tópico como uma categoria híbrida, o qual se estrutura hierarquicamente de forma organizada e sintaticamente de modo linearizado no discurso. Na sentença, o tópico é mencionado pelo falante e pode ser representado por um SN pleno, por um pronome ou por anáfora zero. Na proposta de Givón, está também incluída a idéia de que, no texto, certos tópicos recobrem outros, de tal forma que é legítimo falar em tópicos e subtópicos. Para esse autor, "Topicality is a property of the nominal participants (referents' NPs) in clauses. Propositional information about states or event, coded as clauses, tends to be about same participant(s) in the state/event" (1995, p. 201).

\footnotetext{
De acordo com Pontes (1987, p. 65) "na literatura americana de origem transformacionalista, os lingüistas costumam distinguir, entre as construçōes de tópico, aquelas que são geradas através de uma regra de Topicalização (Top) das que o são através de uma regra de Deslocamento à Esquerda (D.E.)". Essa distinçāo é proposta por Ross (1967) e caracteriza-se, basicamente, pela ausência de um pronome cópia nas construçōes com tópico, enquanto que nas construçōes com deslocamento à esquerda, o pronome cópia aparece. Para Ross apud Pontes (Op. Cit.) numa sentença como "Beans I don't like" ocorre tópico uma vez que não há o pronome cópia; já em "The man my father works with in Boston, he's going to tell police that ..." ocorre deslocamento à esquerda, pois o pronome cópia está aí retomando o elemento deslocado.
} 
No entender desse lingüista, quando um "estado" ou "evento" é topicalizado, ocorre sempre uma nominalização, daí o sujeito ou o objeto passa a constituir outra sentença. Na concepção de Pontes, mesmo que de forma pouco explícita, essa idéia também está presente. É só lembrar que a autora diz que todo SN pode ser tópico. Em Givón, além de se afirmar essa ocorrência, demonstra-se como ela ocorre.

\section{a. Topical agent}

He surprised Sylvia by showing up with flowers.

\section{b. Topical event}

His showing up with flowers surprised Sylvia.

Para Givón (1995), as sentenças acima são codificadas de duas maneiras distintas: em a) "the agent is topical, and thus occupies the subject position"; em b) "the whole event clause is topical, and is thus nominalized and made the subject". De acordo com Givón, a topicalidade não constitui um fenômeno no nível da sentença, mas sim no nível do discurso, muito embora haja uma manifestação gramatical "at the clause level", ou seja, no nível da sentença. O tópico é, portanto, uma noção discursiva codificada pelos falantes e depreendida pelos ouvintes.

De forma muito sumária, convém apontar alguns aspectos relevantes da proposta de Givón $(1995)^{6}$, no que se refere à topicalização. O tópico, na concepção givoniana, constitui um domínio funcional complexo, não é uma entidade atômica, discreta, é antes uma noção escalar que se manifesta num contínuo. A esse

Saliente-se que as questōes aqui colocadas acerca do tópico tomam por base Givón (1995). Há, no entanto, propostas mais recentes desse autor, às quais não se teve acesso quando da elaboração deste texto. 
respeito, Givón propõe uma escala que implica o nível de continuidade da codificação do tópico. Nessa escala, são incorporados elementos fonológicos, morfológicos e sintáticos: anáfora zero, pronome átono, pronome tônico, $\mathrm{SN}$ definido deslocado para a direita, SN definido em ordem neutra, SN deslocado para a esquerda, SN em topicalização contrastiva, construção clivada / de foco e SN indefinido referencial.

Ainda em relação à topicalidade, Givón apresenta dois itens - acessibilidade e importância - que parecem relevantes, a saber: a) "informação mais importante ou urgente tende a ser colocada primeiro no fluxo"; b) "informação menos acessível ou menos previsível tende a ser colocada primeiro no fluxo". Isso implica dizer que os constituintes topicalizados são sempre informação já conhecida do ouvinte, mas o falante quer prender a atenção do seu destinatário com uma informação julgada por ele (o falante) importante.

Esses elementos têm sido considerados por Givón como subitens da topicalidade, os quais são definidos, respectivamente, por anáfora e por catáfora. Daí é natural que os tópicos apareçam na posição inicial do discurso como forma de codificar informações imprevisíveis e/ou importantes. Nesse aspecto, a proposta de Givón aproxima-se da dos demais autores (PONTES e PEZATTI), sobretudo no que diz respeito à posição do tópico nas construções tópicas.

Tomando-se a sentença (2) d "A UFAL, à noite, as aulas vai até dez horas e olhe lá", a título de exemplificação, em que "a UFAL" é o constituinte topicalizado, é possível perceber que se trata de uma informação sobre a qual o falante quer centrar a atenção do ouvinte. Considerando o contexto ${ }^{7}$ em que ela foi produzida, não se pode

Alunos da própria UFAL conversando entre si nos corredores da Instituição sobre o horário de funcionamento desta em relação a outras instituiçōes de ensino superior de Maceió. 
deduzir que o constituinte topicalizado é uma informação nova ou pouco previsível para o ouvinte. Trata-se, antes, de uma informação tida como relevante para o falante e, naquela situação discursiva específica, passada para o ouvinte. Ora, o falante poderia topicalizar qualquer um dos SNs da sentença - "à noite", "as aulas" e assim por diante -, no entanto, não o faz. Por quê?

\subsection{Pezatti}

Tomando a linguagem com um "instrumento usado para propósitos essencialmente comunicativos" Pezatti (1998, p. 133) diz que "só é possível compreender adequadamente as expressōes lingüísticas se forem consideradas operando em circunstâncias efetivas de interação verbal". A partir dessa concepção de linguagem, a autora justifica a necessidade de se analisar a língua, a que ela chama de estrutura gramatical, a partir de contextos distintos, o que implica a atribuição de diferentes funções pragmáticas aos constituintes das sentenças. Funções pragmáticas, segundo a autora, dizem respeito "ao conjunto completo de conhecimento, crença, suposições, opiniōes e sentimentos disponíveis ao falante no momento da interação" (PEZATTI 1998, p. 134).

De antemão, já se pode notar que a autora não terá o problema de tratar funções sintáticas como sujeito e predicado por funçōes pragmáticas como tópico, foco etc. Isso fica evidente no momento em que ela define funções pragmáticas. Estas, de acordo com o que propōe a autora, nada têm a ver com a noção de sujeito e ou de predicado. Essa autora adota a proposta de Dik (1980), que determina três níveis de função na descrição das expressōes lingüísticas, a saber:

\footnotetext{
1. Semantic functions: Agent, Goal, Recipient, etc;

2. Syntactic functions: Subject and Object;

3. Pragmatic functions: Theme and Tail, Topic and Focus.
} 
Para Dik (1980, p. 3):

Functional Grammar is called "functional" not only because it is based on a functional view of the nature of language, but also because functional or relational notions, as opposed to categorial notions, are given a central role in the description of linguistic expressions.

Parece que o trato feito dessa forma presta-se a não pensar, por exemplo, que em sentenças do tipo "O João, ele é professor" há dois sujeitos, o que seria um equívoco. Veja-se, então, o que propõe a autora para a questão do tópico.

Inicialmente, ela aponta que há "uma grande confusão na consideração das funções pragmáticas tópico, foco, antitópico, tema etc" (PEZATTI, 1998, p. 134). Quer, com isso, dizer a autora que, na literatura sobre as funçōes pragmáticas, há divergência entre os autores no tocante aos conceitos veiculados. Em relação ao tópico, por exemplo, há quem o trate como constituinte deslocado à esquerda, ou simplesmente como informação dada e, por vezes, é confundido com sujeito, categoria sintáticosemântica, e ainda com tema, categoria também pragmática, mas distinta de tópico.

Tomando como fundamento a proposta de funcionalismo de Dik (1980), a qual sustenta que cada língua tem um ou mais padrões funcionais para a ordenação dos constituintes sentenciais, conforme representação no esquema abaixo, a autora sugere uma definição, segundo ela, precisa sobre o que é tópico.

A partir do esquema dado, 
P2, P1 (V) S (V) O (V), P3 ${ }^{8}$

\begin{tabular}{|c|l|}
\hline P1 & Tópico ou foco. \\
\hline P2 & Posição reservada para tema. \\
\hline P3 & Posição reservada para antitema. \\
\hline S & Sujeito. \\
\hline O & Complemento. \\
\hline V & Verbo. \\
\hline (V) & Verbo. \\
\hline , (VIRGULA) & Indica pausa entonacional. \\
\hline
\end{tabular}

Pezatti sugere que a possível confusão entre tema e tópico se desfaz, uma vez que este só pode ocupar a posição de P1 enquanto aquele, a de P2.

Para Pezatti (1998), quando se tem algum constituinte da predicação que se encontra na posição de $\mathrm{P} 2$, pode haver o equívoco de concebê-lo como tópico, como o faz Pontes (1987), vejamos:

(3)

De dinheiro, a Vânia não entende nada.

Em Dik (1980, p. 20), lê-se: "the first preference is accounted for by assumption that all languages have one or more "functional patterns" which difine a number of crucial positions for constituents to go to. All these functional patterns are in turn hypothesized to conform to the following language-independent patternschema: Theme, $P 1(V) S(V) O(V)$, Tail", donde se conclui que Pezatti e Camacho fizeram algumas adaptaçōes ao esquema proposto por Dik, a partir das quais resolveram chamar a posiçāo Theme de P2 e Tail de P3. Embora pareça irrelevante esta observação, já se fizeram questionanamentos sobre o porquê de P2 nāo ser P1, por exemplo, e P1 ser P2. Para efeito do desse trabalho, no entanto, adotar-se-á a nomenclatura usada por Pezatti e Camacho, uma vez que nāo se teve acesso a todos os textos de Dik - o texto de Dik citado pelos autores é de 1981a, é possivel que o autor tenha dito P2, P3, enfim, são hipóteses. 
De acordo com o arcabouço teórico adotado por Pezatti, o constituinte de dinheiro, por ocupar a posição P2, só pode exercer a função pragmática de tema; já o constituinte a Vânia, por ocupar a posição P1, exerce a função pragmática de tópico, mas também acumula a função sintática de sujeito.

Em relação a tópico e sujeito, embora muitas vezes o mesmo constituinte exerça a função sintática de sujeito, a função pragmática de tópico e ainda a função semântica de agente, não há como confundir porque sāo funçōes relacionadas a componentes distintos, defendem Pezatti e Dik.

Ainda com base em Dik, Pezatti classifica as funções pragmáticas em intra e extra-oracionais. São intra-oracionais as funções representadas por P1, ou seja, tópico e foco. Estas são sempre atribuídas a algum elemento da predicação. Já as extraoracionais são aquelas representadas por P2 e P3 (Cf. PEZATTI, 1998). O que parece interessante nessa distinção é a possibilidade de se estabelecer critérios para distinguir tópico das demais funções pragmáticas. Ora, se o tema, por exemplo, está sempre em P2, e, portanto, fora da predicação, jamais será confundido com o tópico; se o antitema está em P3 e, portanto, fora da predicação e à direita dela, jamais pode ser confundido com tópico, foco, tampouco com tema.

Dessa forma, o que poderia causar algum tipo de dificuldade seriam os constituintes tópico e foco, já que ambos se inserem dentro da predicação. No entanto, Pezatti (1998) apresenta algumas características do foco como: saliência da informação, marcação entonacional e contraste com algum item da predicação, as quais não se fazem presentes no tópico. Em sendo assim, a confusão a que Pezatti faz referência seria desfeita.

Veja-se então como a autora analisa, com base no esquema acima, as construções tópicas. 
$\mathrm{Em}$

O empresário havia saído de Sorocaba por volta das $12 \mathrm{~h}$, com destino a Taquarituba $(315 \mathrm{~km}$ a oeste de São Paulo), segundo CMM, primo de $M J$ e administrador da construtora. Ele levava consigo cerca de US\$ 40 mil para fazer pagamento de funcionários que trabalhavam na construção de casas populares,

os termos sublinhados exercem a função sintática de sujeito, função semântica de agente e função pragmática de tópico. Ela diz ainda que a função de tópico "apresenta uma entidade sobre a qual a predicação predica alguma coisa” (PEZATTI, 1998, p. 137), o que nos parece uma afirmação por demais vaga.

Dik (1989 apud PEZATTI, 1998, p. 144) diz que o tópico "é um conceito discursivo, já que qualquer discurso, tomado no sentido mais amplo de texto coerente, "fala" necessariamente a respeito de entidades" a que Dik denomina Tópico-Discursivo. A partir desse ponto de vista, surgem as noções de Tópico-Novo (Top-N), TópicoDado (Top-D), SubTópico (Sub-Top) e Tópico-Retomado (Top$\mathrm{R})$, conceitos que não serão discutidos neste espaço, uma vez que estão no nível do discurso e não no da sentença, campo delimitado para a observação do tópico neste artigo.

Em (4), pode-se observar o preenchimento de todas as funçōes pragmáticas do esquema proposto por Pezatti.

Bebida alcoólica, ele gosta muito, o Pedro.

[...] bebida alcoólica é o Tema, que ocupa a posição mais à esquerda da predicação; o pronome ele, por acumular concomitantemente a função pragmática 
de Tópico e a sintática de Sujeito da predicação, posiciona-se em P1, lugar reservado aos constituintes que têm uma função especial, seja gramatical ou pragmática; já o constituinte o Pedro, por esclarecer anaforicamente a referência do pronome cle, é pragmaticamente um Antitema, e ocupa a posição P3, reservada para essa função. (PEZATTI, 1998, p. 136).

\section{Considerações finais}

Do que foi dito até então, algumas considerações. Em primeiro lugar, é bom lembrar que, embora adotando perspectivas funcionalistas distintas, os autores a que se fez menção, de alguma forma, são coerentes com suas propostas dentro dos seus limites de alcance. Pode-se dizer que há alguma complementaridade entre cada proposta. Considerando-se a descrição feita por Pontes acerca das características do tópico nas línguas de tópico, é possível contrastálas com o esquema proposto por Pezatti para as funções pragmáticas dos constituintes sentenciais, a fim de se obter análises mais precisas acerca do tópico. Para o mesmo fim, é possível lançar mão da proposta givoniana de acessibilidade e importância de informaçōes.

As comunhões são possívcis, "mas as ressalvas a cada proposta, necessárias. No que diz respeito a Pontes, é válido lembrar a distinção que a autora faz entre tópico e deslocamento à esquerda. O que distingue um do outro, segundo a autora, é a presença do pronome cópia no deslocamento à esquerda e sua ausência nas construções tópicas. Essa é uma distinção não mais feita por Pezatti, por exemplo. Esta autora argumenta que é um princípio da Gramática Funcional a não movimentação de um constituinte de uma posição a outra, o que implica considerar as construções com deslocamento à esquerda também com construções tópicas. É bem verdade que nem sempre o que Pontes considera como tópico equivale à noção desse item na perspectiva de Pezatti. Muitas vezes, 
o que é tópico na perspectiva adotada por Pontes constitui tema na proposta de Pezatti, e tema aqui não é sinônimo de assunto, como propõe Givón, dentre outros autores.

Uma idéia proposta por Pezatti (1992 - 1998) que carece de ser refutada diz respeito a uma enorme confusão acerca do que é um tópico. Confrontando a proposta dessa autora com a de Pontes e de Givón, pode-se observar que não se trata de uma confusão conceitual, mas sim de perspectivas distintas de se observar o tópico. Aqui é pertinente trazer à memória a célebre frase de Saussure (1973, p. 15), em que se lê "é o ponto de vista que cria o objeto".

Com isso, a proposta da referida autora acerca do tópico não se torna desmerecida, até porque é muito coerente, como as demais o são. No entanto, parece pouco convincente tomar-se um quadro teórico dentro do funcionalismo e, a partir disso, desconsiderar as outras vertentes funcionalistas, a fim de sustentar essa suposta "confusão" conceitual sobre o tópico.

Sem dúvida a proposta apresentada por Pezatti baseada no esquema elaborado por $\operatorname{Dik}(1980)$ - P2, P1 (V) S (V) O (V), P3 - é bastante razoável para a localização e ou identificação do tópico, a partir da posição dentro da predicação, já que o tópico é, de acordo com esses autores, um constituinte intra-oracional. Nessa perspectiva, a posição define o tópico, mas não só ela.

Aqui convém lembrar Givón, que embora sumariamente apresentado em termos teóricos, concebe o tópico como categoria manifesta na sentença, mas de caráter discursivo e, dessa forma, pode, também, ser analisado no nível do texto. Os demais autores a que faço menção também comungam dessa opinião. Dik (1989 apud PEZATTI, 1998, p. 144) diz que "o Tópico é um conceito discursivo, já que qualquer discurso, tomado no sentido mais amplo de texto coerente, "fala" necessariamente a respeito de entidades".

Em Pontes (1987), lê-se que o tópico está no limiar ente a sintaxe e o discurso, o que a autora chama de uma "quase-sintaxe", 
ou seja, a lingüista reconhece que o tratamento do tópico não pode ser feito apenas do ponto de vista da estrutura gramatical, da sintaxe - há uma necessidade de se recorrer ao discurso, aqui entendido como fala mais todo o contexto em que essa fala é produzida.

De modo geral, a breve passagem pelos autores supracitados permite algumas conclusões: a) a categoria tópico carece ainda de estudos mais detalhados que lhe dêem conta no nível sintático, semântico, pragmático, textual e discursivo; b) a categoria tópico pode ser analisada no nível da sentença ou do texto; c) a categoria tópico pode ser analisada sob perspectiva distintas do Funcionalismo e até de perspectivas formais, sem que, no entanto, uma determinada análise invalide as demais, como tenta fazer Pezatti. Os itens, ora, expostos são apenas uma minúscula parte do leque de possibilidades de que dispõe a língua(gem), de modo geral, e do tópico, em particular.

\section{Referências}

CAMARA JR. J. M. Dicionário de linguística e gramática. 13. ed. Petrópolis, RJ: Vozes, 1986.

. Problemas de lingüística descritiva. 18. ed. Petrópolis, RJ: Vozes, 2000.

CRYSTAL, D. Dicionário de lingïística e fonética. Rio de Janeiro: Jorge Zahar Editor, 2000.

CUNHA. M. A. F da et al. Lingiiística funcional: teoria e prática. Rio de Janeiro: DP \& A, 2003.

DECAT, M. B. N. Construçôes de Tópicos em Português: uma abordagem diacrônica à luz do encaixamento no sistema pronominal: In: TARALLO, F. (org.). Fotografias sociolingiiísticas. Campinas: Pontes, 1989.

DIK, S. C. Studies in functional grammar. London: Academic Press, 1980. 
. Functional grammar. Dordrecht: Foris Publications, 1981.

DILLINGER, M. Forma e função na lingiústica. DELTA. 1991. vol.7, $\mathrm{n}^{\circ} 1$ : 395-408.

DUBOIS, J. et al. Dicionário de lingiística. 9. ed. São Paulo: Cultrix, 1993.

GIVÓN, T. Functionalism and grammar. Amsterdam: John Benjamins, 1995.

LI, C. N. e THOMPSON, S. A. Subject and topic: a new typology of. language. In: LI, C. N. (Org.) Subject and topic. New York: Academic Press, 1976.

LYONS, J. Linguagem e lingiiística: uma introdução. Rio de Janeiro: LTC, 1987.

MARTELOTTA, M. E. e AREAS, E. K. A visão funcionalista da linguagem no século XX. IN: CUNHA. M. A. F da et al. Linguiistica funcional: teoria $\mathrm{e}$ prática. Rio de Janeiro: DP \& A, 2003. p. 17-28.

MUSSALIM, F e BENTES, C. (Orgs). Introdução à lingüística. São Paulo: Cortez, 2004. V. 3.

NASCIMENTO, M. Teoria gramatical e mecanismos funcionais do uso da língua. DELTA, 1990. vol. 6, nº1: 83-98.

NEVES, M. H. M. Gramática funcional. São Paulo: Martins Fontes, 1997.

PEZATTI, E. G. A ordem de palavras em português: aspectos tipológicos e funcionais. Tese de Doutorado. UNESP/Araraquara. Araraquara-SP, 1992.

. Constituintes pragmáticos em posição inicial: distinção entre tema, tópico e foco. São Paulo: Alfa, 1998. No 42, p. 133 -150.

PEZATTI, E. G. e CAMACHO, R. G. Ordenação dos constituintes na sentença: uma interpretação funcional. São Paulo: Alfa, 1997. No 41(esp.), p $99-$ 126. 
PONTES, E. S. L. O tópico do português do Brasil. Campinas, SP: Pontes, 1987.

SAUSSURE, F. de. Curso de lingiiística geral. 5. ed. São Paulo: Cultrix, 1973.

VALENÇA, P. J. da S. Sintaxe: forma ou função? IN: MOURA, D. (Org). Reflexões sobre a sintaxe do português. Maceió: EDUFAL, 2005, p. 189-213. 